Canadian

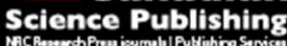

Applied Physiology, Nutrition, and Metabolism Physiologie appliquée, nutrition et métabolisme

\title{
Muscle sympathetic activity in resting and exercising humans with and without heart failure
}

\begin{tabular}{|r|l|}
\hline Journal: & Applied Physiology, Nutrition, and Metabolism \\
\hline Manuscript ID & apnm-2015-0289.R1 \\
\hline Manuscript Type: & Article \\
\hline Date Submitted by the Author: & 05-Aug-2015 \\
\hline Complete List of Authors: & $\begin{array}{l}\text { Notarius, Catherine; University Health Network/Mount Sinai Hospital, } \\
\text { Medicine/Cardiology; } \\
\text { Millar, Philip; University of Guelph, Human Health and Nutritional Sciences } \\
\text { Floras, John; University Health Network and Mount Sinai Hospital, } \\
\text { Cardiology }\end{array}$ \\
\hline Keyword: & $\begin{array}{l}\text { exercise < exercise, autonomic nervous system < nervous system, } \\
\text { exercise training < exercise, heart failure, microneurography }\end{array}$ \\
\hline &
\end{tabular}


3 Catherine F. Notarius PhD ${ }^{1}$, Philip J. Millar PhD ${ }^{2}$, John S. Floras MD, DPhil, FRCPC ${ }^{3}$

$4{ }^{1}$ University Health Network and Mount Sinai Hospital Division of Cardiology, University of

5 Toronto. Address: 6ES:414, Toronto General Hospital, University Health Network, 200

6 Elizabeth St. Toronto, ON, Canada, M5G 2C4. Email: c.notarius@utoronto.ca

$7 \quad{ }^{2}$ Department of Human Health and Nutritional Sciences, University of Guelph, 341A ANNU, 50

8 Stone Road East, Guelph ON, Canada, N1G 2W1. Email: pmillar@uoguelph.ca

$9 \quad{ }^{3}$ University Health Network and Mount Sinai Hospital Division of Cardiology, University of

10 Toronto. Address: Ste.1614, Mount Sinai Hospital, 600 University Ave. Toronto, ON, Canada,

11 M5G 1X5. Email: john.floras@utoronto.ca

12 Corresponding author: C.F. Notarius Ph.D., 6ES:414, Toronto General Hospital,

13 University Health Network, 200 Elizabeth St. Toronto, Ontario; Canada, M5G 2C4

14 Tel: (416) 340-4755; Fax: (416) 340-5506; email: c.notarius@utoronto.ca

15 Word Count: 8,956 
1

2

3

4

5

6

7

8

10

11

12

\section{ABSTRACT}

The sympathetic nervous system is critical for coordinating the cardiovascular response to various types of physical exercise. In a number of disease states, including human heart failure with reduced ejection fraction (HFrEF), this regulation can be disturbed and adversely affect outcome. The purpose of this review is to describe sympathetic activity at rest and during exercise in both healthy humans and those with HFrEF and outline factors which influence these responses. We focus predominately on studies which report direct measurements of efferent sympathetic nerve traffic to skeletal muscle (muscle sympathetic nerve activity; MSNA) using intraneural microneurographic recordings. Differences in MSNA discharge between subjects with and without HFrEF both at rest and during exercise and the influence of exercise training on the sympathetic response to exercise will be discussed. In contrast to healthy controls, in HFrEF MSNA increases during mild to moderate dynamic exercise. This increase may contribute to the exercise intolerance characteristic of HFrEF by limiting muscle blood flow and may be attenuated by exercise training. Future investigations are needed to clarify the neural afferent mechanisms which contribute to efferent sympathetic activation at rest and during exercise in HFrEF.

Keywords: exercise, heart failure, HFrEF, microneurography, muscle sympathetic nerve activity, exercise training, peak oxygen uptake 
1

\section{INTRODUCTION}

The sympathetic nervous system plays an essential role in regulating and coordinating the reflex cardiovascular response to exercise in both health and disease (Mitchell, 1990). A variety of methods are used to measure sympathetic nervous system activation in humans. These range from non-invasive techniques such as spectral analysis of heart rate variability (Task Force of the European Society of Cardiology and North American Society of Pacing and Electrophysiology, 1996; Notarius et al., 1999b) to quantitation of plasma norepinephrine (NE) (Jensen et al., 1994), total NE spillover (Esler et al., 1988) or spillover across specific organs such as the heart, kidney and skeletal muscle (Kingwell et al., 1995; Dinenno et al., 1999; Grassi and Esler, 1999). By contrast, with microneurography, efferent sympathetic nervous discharge can be recorded directly from the innervation of blood vessels in skeletal muscle or skin (Valbo et al., 1979). Muscle sympathetic nerve activity (MSNA) is pulse synchronous and expressed as either number of bursts per minute (frequency) or multi-unit number of bursts per 100 heart beats (incidence) or total MSNA which integrates burst amplitude (normalized burst area) (Valbo et al., 2004). Measurements of MSNA offer a more sensitive method of detecting and quantifying sudden changes in sympathetic nervous outflow than do plasma NE concentrations (Floras et al., 1986; Grassi et al., 2008). Further, unlike the determination of NE spillover, changes in MSNA appear immediately rather than after a lag time of minutes. Simultaneously acquired sympathetic nerve recordings to different muscle groups are congruent both at rest and when elevated in response to the application of lower body negative pressure, implying that a recording from one location represents sympathetic outflow to muscle in general (Rea and Wallin, 1989). Because MSNA represents the efferent limb of the skeletal muscle reflex arc, it is of particular interest to 
1 those investigating responses to physical exercise. Importantly, to do so requires a stationary

2 limb.

3 Sympathoexcitation, or elevated sympathetic activity at rest, is a hallmark of untreated

4 patients with heart failure due to reduced ejection fraction (HFrEF) (Leimbach et al., 1986).

5 When present, it is associated with an adverse prognosis (Barretto et al., 2009). Abnormal

6 sympathetic control may also contribute to the exercise intolerance observed in HFrEF. Our

7 group was the first to report a relationship between the extent to which MSNA is increased in

8 HFrEF patients and their level of exercise intolerance, independent of left ventricular ejection

9 fraction (LVEF) (Notarius et al., 1999a; Notarius et al., 2014).

In this review we will focus on the response of efferent muscle sympathetic nerve traffic to

11 static and dynamic exercise in healthy subjects and patients with HFrEF. To frame this

12 discussion we first will summarize known differences in resting MSNA between these two

13 groups. Second, we will discuss sympathetic overactivity at rest in HFrEF and how it impacts

14 exercise tolerance. Third, we will review the efferent sympathetic response to acute static and

15 dynamic exercise in HFrEF and identify possible key mechanisms. In both healthy control and

16 HFrEF cohorts, we will briefly evaluate the effect of exercise training on sympathetic activity.

17 Finally, we will identify potential future research directions. 
Age and sex are two major influences on resting sympathetic nerve activity in healthy

2 subjects (Ng et al., 1993). Muscle sympathetic firing rates are generally low in young healthy

3 adults (Floras and Hara, 1993). Across all ages, MSNA is higher in men than women (Seals and

4 Esler, 2000). Interestingly, these age and sex differences in MSNA are not reflected in concurrent measurements of plasma NE concentrations (Seals and Esler, 2000), underscoring the

6 limitation of this indirect assay for between- subject comparisons of sympathetic activity.

Sympathetic outflow to arterial resistance vessels is greater in healthy older compared with younger men. This impacts vasoconstrictor tone; older men have higher vascular resistance

9 and lower conductance, which is its inverse (Hart et al., 2009). There is a significant negative

10 correlation between femoral blood flow or vascular conductance (flow/pressure) and MSNA

11 burst frequency in men (Dinenno et al., 1999) but not women (Moreau et al., 2003). These

12 observations belie the common assumption that reductions in vascular conductance always

13 reflect sympathoexcitation (Seals and Esler, 2000; Hart et al., 2009). We reported a similar

14 disassociation between vascular resistance (pressure/flow) in the forearm and MSNA in middle-

15 aged fit men, but a positive relationship between the two variables in similarly aged sedentary

16 men (Notarius et al., 2012). In those experiments MSNA was increased reflexively by applying

17 increasing levels of lower body negative pressure to reduce central venous pressure and unload

18 gradually the arterial baroreceptors.

In addition to age, sex and fitness, posture and body weight also can affect resting

20 MSNA. MSNA is lower in young healthy subjects in the supine vs upright posture (Ray et al.,

21 1993). This difference was explained by higher central venous pressure, implicating stimulation

22 of cardiopulmonary baroreceptors as the responsible reflex sympathoinhibitory mechanism.

23 Obesity also is associated with a marked sympathetic activation: MSNA of young normotensive 
1 obese individuals is approximately double that of their non-obese control counterparts even in

2 the absence of coexisting sleep apnea (Grassi et al., 2014).

3 Repeat microneurographic recordings in a single healthy individual over time yield

4 generally reproducible values (Valbo et al., 2004). However, even when the influence of these

5 identified factors is accounted for, MSNA at rest can vary considerably between subjects,

6 particularly in women (Hart et al., 2009). At the vascular level, an increased neurogenic stimulus

7 to vasoconstriction may be offset by diminished alpha adrenoceptor responsiveness. For

8 example, Charkoudian et al. (2006) reported that healthy young men and women with higher

9 MSNA at rest had less vasoconstriction in response to both exogenous NE as well as NE release

10 stimulated by intrabrachial tyramine, and concluded that such inter-individual variability in

11 vascular adrenergic responsiveness could offset increased central sympathetic drive so as to

12 maintain normal blood pressure regulation.

Whether this healthy equilibrium between the impact of alterations in resting MSNA and

14 adrenergic responsiveness on vascular resistance is altered with age, posture, body mass, or in

15 conditions such as hypertension and heart failure is an important subject for further research.

\section{EXERCISE}

In healthy subjects, sympathetic activity increases during dynamic exercise in order to redistribute blood flow to the working muscles and increase oxygen delivery (Mitchell, 1990; Hasking et al., 1988). MSNA responses during exercise were first studied using a handgrip model. Sympathetic nerve activity was recorded from the peroneal (fibular) nerve of a stationary leg during either static or dynamic exercise of various intensities. 
The muscle metaboreflex is the primary sympathoexcitatory mechanism elicited by static exercise (Mark et al., 1985; Hansen et al., 1994). Its potency is revealed by the post-handgrip ischemia manoeuvre. This traps within the forearm the metabolites released by muscle contraction, prolonging stimulation of type III and IV muscle afferents. This manoeuvre was designed to eliminate any confounding influence of both central volitional effects and the mechanical effect of muscle contraction (muscle mechanoreflex) on MSNA (Mark et al., 1985). MSNA is increased during the second minute of static handgrip at an intensity of $30 \%$ or greater of maximum voluntary contraction (MVC) whereas dynamic handgrip shows no such elevation in MSNA unless flow is diminished by vascular occlusion during exercise (Victor et al., 1987). This is considered analogous to the low flow state evident in HFrEF patients. Thus, sympathetic responses are intensity- and exercise mode-dependent, with the muscle metaboreflex active during both dynamic and static handgrip, (Hansen et al., 1994; Mark et al., 1985) and maintained during post-handgrip ischemia (Victor et al., 1987). However, data by others who observed an early increase in MSNA during dynamic handgrip and a prompt return to baseline during postexercise ischemia, emphasize an important contribution of the muscle mechanoreflex to the net MSNA response (Batman et al., 1994).

A more recent study by Stickland (2008), involving healthy young subjects, demonstrated that the increase in MSNA in response to dynamic handgrip exercise at 50\% MVC could be reduced when the subject was breathing $100 \%$ oxygen, whereas there was no effect at rest, suggesting that the arterial chemoreflex contributes importantly to the sympathoexcitatory response to dynamic handgrip (Stickland and Miller, 2008). In a subsequent study using a different exercise mode, changes in blood flow and conductance with leg exercise during 
1 hyperoxia followed a similar time course as the previous reductions in MSNA (Stickland et al.,

2 2011).

3 A leg extension model, engaging a much larger muscle mass than the forearm, was

4 developed to study blood flow responses during two or one-legged exercise. This made it

5 possible to measure MSNA in the contralateral leg during single leg extension under both

6 dynamic (isotonic) or static (isometric) conditions (Andersen et al., 1985). Using this model, Ray

7 and colleagues found a decrease in MSNA with upright mild intensity exercise (20, 30 and 40

8 watts), rather than the increase anticipated from previous static and dynamic handgrip data. This

9 decrease was greatest at the lowest work rate (Ray et al., 1993). Ray et al. also measured MSNA

10 during a 30 watt work rate while recording central venous pressure (CVP) and compared supine

11 to upright posture. In the upright posture, resting CVP was lower compared with supine yet

12 increased during exercise due to central translocation of blood from the mechanical pumping

13 effect of rhythmic muscle contractions with exercise. There was a drop in CVP and no change in

14 MSNA with subjects supine, but an increase in CVP and a fall in MSNA when they were

15 upright. The latter was attributed to stimulation of sympathoinhibitory cardiopulmonary

16 baroreceptors by the former (Ray et al., 1993).

Concurrently, Saito and Mano (1991) demonstrated that the mode of leg exercise affects

18 the MSNA response. They compared one-legged cycling at up to $30 \%$ of peak oxygen uptake

19 (VO2peak) to one-legged static leg extension and measured MSNA in the tibial nerve of the

20 contralateral resting leg. They showed a work rate- related decrease in MSNA during mild

21 exercise up to 25 watts but not at 50 watts, whereas MSNA significantly increased during static

22 leg exercise performed at 20\% MVC (Saito and Mano, 1991). Subsequent experiments involving

23 MSNA recorded from the median nerve of the arm during bilateral cycling showed a drop in 
1 burst frequency at work rates less than $40 \%$ of VO2peak but an increase at rates of 60 and $74 \%$

2 VO2peak (Saito et al., 1993).

3 Using the same model, this group (Katayama et al., 2011) and others (Ichinose et al.,

4 2008) confirmed that sympathetic nerve traffic in the median nerve of the arm is diminished at

5 both absolute and relative mild to moderate work rates, but increased during heavy or exhaustive

6 leg cycling (Ichinose et al., 2008). An increase in MSNA at 40\% of VO2peak occurred only

7 when subjects were breathing a hypoxic gas mixture of $12.7 \%$ oxygen. These findings may have

8 implications for those HFrEF patients with compromised oxygen delivery during exercise

9 (Esposito et al., 2010). The literature regarding MSNA responses to exercise in healthy subjects

10 is summarized in Table 1.

11 In sum, MSNA during exercise in healthy subjects varies according to type and intensity

12 of exercise as well as the amount of active muscle mass. In contrast to static exercise, mild to

13 moderate dynamic exercise yields a drop in MSNA with increases above baseline only at

14 intensities exceeding $40 \%$ of $\mathrm{VO} 2$ peak. MSNA responses under specific exercise conditions are

15 based on the net response of the individual afferent reflexes recruited and the involvement of

16 feed-forward central command.

17 EXERCISE TRAINING

In healthy sedentary subjects, six weeks of high intensity endurance exercise training had

19 no effect on resting MSNA, but the anticipated drop in MSNA burst frequency during moderate

20 intensity one-legged cycling became markedly attenuated by the third minute of exercise (Ray,

21 1999). The absence of any change in resting MSNA after endurance training is a consistent

22 finding in the literature (Carter and Ray, 2015) and is compatible with cross-sectional data 
1 reporting no difference in resting MSNA between trained and untrained young (Seals, 1991;

2 Svedenhag et al., 1984), middle-aged, or older healthy subjects (Sheldahl et al., 1994; Notarius et

3 al., 2012). In contrast, elite endurance athletes exhibited an increase in resting MSNA compared

4 to sedentary individuals who were matched for adiposity (Alvarez et al., 2005). This observation

5 highlights the importance of considering the potential confounding influence of body mass when

6 comparing trained and untrained subjects. Others have also showed a decrease in MSNA during

7 both isometric (Somers et al., 1992) and non-fatiguing dynamic handgrip (Sinoway et al., 1996)

8 following unilateral forearm endurance training.

9 In contrast, the response to resistance training is less consistent. Saito and colleagues

10 found that MSNA actually increased following 4 weeks of maximal handgrip training, although

11 it reverted to baseline after 4 weeks of detraining (Saito et al., 2009). This result is consistent

12 with cross-sectional data showing higher MSNA at rest in bodybuilders compared with sedentary

13 controls (Sinoway et al. 1992). However, others have reported no change at rest either following

14 isometric handgrip training (Ray and Carrasco, 2000), or whole body resistance training (Carter

15 et al., 2003). Also, 4 weeks of submaximal intensity static handgrip training had no effect on the

16 magnitude of increase in MSNA during handgrip (Saito et al., 2009).

18 during exercise, but from the limited and discordant data available it is less certain whether 19 resistance exercise training achieves similar effects. 
In many treated heart failure patients with relatively preserved exercise capacity, MSNA when measured at rest is similar to that of age and sex matched healthy controls (Notarius et al., 2001). However, the majority of patients with HFrEF have elevated resting sympathetic activity. This, is now recognized to be an independent predictor of premature mortality (Barretto et al., 2009; Cohn et al., 1984; Kaye et al., 1995; Petersson et al., 2005). The magnitude and time course of elevated sympathetic outflow across all vascular beds is not uniform but organ specific (Rundqvist et al., 1997). An initial elevation in cardiac NE spillover precedes a later doubling of skeletal muscle, total body and renal NE spillover (Rundqvist et al., 1997). The relative increase in cardiac NE spillover exceeds that of renal NE spillover (Hasking et al., 1986). Importantly, the magnitude of such sympathoexcitation is independent of the degree of LVEF impairment (Ferguson et al., 1990; Notarius et al., 1999a; Notarius et al., 2001).

Most HFrEF patients have exercise intolerance, as evidenced by reduced predicted peak oxygen consumption (VO2peak) relative to healthy controls (Pina et al., 2003). Lower VO2peak also has been identified as an important marker of poor outcome (Stelken et al., 1996) independent of the extent of left ventricular dysfunction (Franciosa et al., 1981; Cohn et al., 1993). Figure 1 depicts representative MSNA recordings from 2 healthy subjects, one older (upper left panel) and $2 \mathrm{HFrEF}$ patients of similar age but with different exercise capacities. This Figure demonstrates the variability in resting MSNA observed normally in healthy subjects (most likely age-related), as well as the relationship between exercise capacity and resting MSNA in HFrEF subjects. MSNA burst frequency is elevated markedly in the HFrEF patient with poor exercise tolerance, compared with the relatively normal values present in the HFrEF patient with preserved exercise capacity (Figure 1, right panels). 
Our group was the first to report a link between VO2peak and resting MSNA in HFrEF (in contrast to age-matched healthy control subjects), raising the hypothesis of a peripheral neurogenic limit to exercise tolerance in this patient population (Notarius et al., 1999a). We subsequently demonstrated that the inverse relationship in HFrEF patients was specific to skeletal muscle in that VO2peak and cardiac NE spillover showed no such association (Notarius et al., 2002). Patients with an ischemic cardiomyopathy (ICM) etiology have a significantly higher mean MSNA burst frequency compared with those of non-ischemic or dilated etiology; although both are higher than mean values for age-matched healthy subjects (Notarius et al., 2007). This could reflect, consistent with our previous work (Notarius et al., 2001), the generally lower values for peak VO2 of ICM patients (Notarius et al., 2007), or represent a reflex sympathoexcitatory response to chronic myocardial ischemia (Floras 2009).

To explain the elevated sympathetic activity present in most HFrEF patients, we and others have proposed several reflex mechanisms involving either augmentation of existing sympathoexcitatory and/or reduced sympathoinhibitory influences, (Azevedo et al., 2000; Dibner Dunlap et al., 1996; Floras, 2001; Floras and Ponikowski, 2015; Millar et al., 2015; Notarius et al., 2001; Schultz et al., 2007). The assumption of a heart failure-induced impairment in arterial baroreflex inhibition was disproved by our discovery of muscle sympathetic alternans which demonstrated that the arterial baroreceptor control of MSNA was preserved in HFrEF patients (Ando et al., 1997b; Floras, 2001). By contrast there is strong evidence for impaired cardiopulmonary baroreflex inhibitory modulation of MSNA (Dibner Dunlap et al., 1996). However, in some individuals paradoxical vasodilation can occur when the cardiopulmonary baroreceptors are unloaded experimentally by lower body negative pressure (Notarius et al., 2009). Our group has previously identified a cardiac-specific sympathoexcitatory reflex related 
1 to increased filling pressure in HFrEF (Azevedo et al., 2000) and recently published evidence

2 supporting an augmented excitatory cardiopulmonary-MSNA reflex response to increased

3 preload which incorporates two distinct single-unit populations with differing firing properties

4 (Millar et al., 2013; Millar et al., 2015). There is also increasing evidence to support overactivity

5 of the muscle metaboreflex (Notarius and Floras, 2007; Notarius et al., 2001; Piepoli and Coats,

6 2007) and arterial chemoreflex (Despas et al., 2012) at rest in patients with HFrEF compared

7 with age-matched controls. Coexisting sleep apnea in HFrEF patients also augments their

8 daytime MSNA, independent of HFrEF etiology (Spaak et al., 2005), but can be inhibited when

9 such patients are treated with nocturnal continuous positive airway pressure (Usui et al., 2005).

10 This supports the concept, recently reviewed by Abboud and Kumar (2014), that persistent

11 daytime elevation of MSNA can result from neuroplastic changes in chronic chemoreceptor

12 sensitivity and in central neural modulation of sympathetic outflow, and that such changes are

13 reversible if obstructive sleep apnea is abolished.

In summary, elevated MSNA at rest in HFrEF patients is related to the extent of exercise intolerance and is independent of the severity of left ventricular dysfunction. Each of ischemic

16 etiology, elevated cardiac preload, and the presence of sleep apnea can contribute to increases in

17 resting MSNA in this population. This elevated sympathetic activity at rest reflects the

18 integration of central neural changes, impaired sympathoinhibitory reflex afferents in response to

19 reduced stroke volume, and excessive sympathoexcitatory compensatory reflex output to the

20 brainstem. The relative importance of each factor can vary from patient to patient and remains an 21 active area of investigation.

\section{EXERCISE}


2 handgrip. MSNA is elevated during static handgrip (usually performed at $30 \% \mathrm{MVC}$ ) compared

3 with age-matched controls (Sterns et al., 1991; Murai et al., 2009). This increase has been

4 attributed in part to the increased probability of multiple firing of single sympathetic fibers

5 (Murai et al., 2009).

The functional consequences of augmented sympathetic responses during exercise include exaggerated peripheral neurogenic vasoconstriction (Crisafulli et al., 2007) and impaired

8 vasodilation (Alves et al., 2007). We hypothesize that in such after-load sensitive patients,

9 exaggerated vasoconstriction in response to muscle metaboreflex activation during dynamic handgrip exercise supports blood pressure, but limits muscle perfusion and thus exercise

11 tolerance. This contrasts with healthy subjects who rely more on increases in cardiac output to

12 elevate blood pressure during exercise. In a dog model of heart failure, metaboreflex activation

13 resulted in a vasoconstriction-mediated rather than a flow-mediated increase in blood pressure

14 (Hammond et al., 2000). Alves et al. (2007) reported that, in contrast to healthy control subjects,

15 patients with advanced heart failure exhibited a blunted reflex vasodilatory response to static

16 handgrip. This was reversed by an intra-arterial infusion of the alpha blocker, phentolamine.

17 Similarly, phentolamine infusion increased muscle vasodilation during mental stress in HFrEF

18 patients (Santos et al., 2005) and reversed paradoxical vasoconstriction observed during hypoxia

19 (Alves et al., 2012). Thus, sympathoexcitation can functionally exaggerate vasoconstriction and 20 impair vasodilation in HFrEF.

We have recorded MSNA during two minutes of both static and mild, moderate and

22 intense levels of dynamic handgrip in HFrEF and age-matched control subjects. To isolate the 23 muscle metaboreflex handgrip was followed immediately by post-exercise circulatory arrest. 
1 MSNA increased in response to handgrip exercise in HFrEF compared with age-matched healthy

2 subjects. The magnitude of this increase differed with exercise mode, intensity, and the patients'

3 baseline fitness level (Notarius et al., 2001). HFrEF patients had an increase in MSNA at a lower

4 threshold than healthy controls during dynamic and static handgrip. This difference was

5 maintained during post-handgrip ischemia but following only static handgrip and the highest

6 intensity of dynamic handgrip (50\% MVC). These findings support a role for the muscle

7 metaboreflex in eliciting sympathoexcitation at these levels of exercise (Notarius et al., 2001)

8 and are consistent with previous observations, made both during and following exhaustive

9 dynamic handgrip at 25\% MVC (Silber et al., 1998). Others have reported that MSNA returns to

10 baseline during post-handgrip ischemia after static handgrip (Sterns et al., 1991) and lower

11 intensity dynamic handgrip (20\% MVC), but is increased during passive exercise, and concluded

12 that it is rather muscle mechanoreflex activation that augments MSNA in HFrEF during low

13 intensity exercise (Middlekauff et al., 2004; Middlekauff and Sinoway, 2007). Importantly, our

14 protocol did not elicit an immediate exercise-induced increase in MSNA. MSNA rose only

15 during the second minute of handgrip, consistent with a primary role for the metaboreflex,

16 particularly during dynamic handgrip in HFrEF (Notarius et al., 2001; Notarius and Floras,

17 2007). Differences between studies with respect to subjects' posture during exercise or their co-

18 morbidities, especially diabetes, could explain these discordant results.

Although it is a pragmatic model, handgrip is not representative of the bulk of real-life

20 day to day physical activity which usually engages much larger muscle mass. However, at

21 present there are limited data available concerning the effects of leg exercise on sympathetic

22 activity in HFrEF. Total body NE spillover is elevated in HFrEF compared to control subjects

23 during both bilateral cycling and one-legged dynamic leg extension exercise modes (Esposito et 
1 al., 2010). Infusion of clonidine, a centrally and peripherally acting alpha-2 receptor agonist,

2 lowers cardiac NE and plasma NE concentrations and increases leg blood flow during dynamic

3 exercise in HFrEF (Azevedo et al., 1999; Lang et al., 1997). However in a comparative study,

4 patients with HFrEF experienced less sympathoinhibition with clonidine compared to healthy

5 controls suggesting decreased central alpha-2 adrenergic sensitivity in HFrEF ( Lang et al.,

6 1997). This may result in less prejunctional alpha-2 mediated inhibition of NE release both

7 centrally and at the peripheral sympathetic nerve terminal, providing an additional mechanism

8 for greater neurogenic vasoconstriction in HFrEF. There also may be up-regulation of arterial

9 alpha-1 adrenoceptors with increased vasoconstrictor sensitivity, as has been demonstrated in a

10 paced canine model of HFrEF (Forster et al., 1989; Forster and Armstrong, 1990). However in

11 human heart failure the transduction of neural input into vascular responses, quantified as the gain of the

12 cross-spectral transfer function between oscillations in MSNA and oscillations in blood pressure, is

13 attenuated relative to healthy matched control subjects (Ando et al. 1997a).

These altered patterns of sympathetic response in HFrEF during submaximal dynamic

16 handgrip exercise and peak leg exercise led us to measure MSNA in one-leg in HFrEF patients

17 while the contralateral leg performed mild and moderate intensity dynamic cycling exercise.

18 Similar to what we had observed previously at rest, we found an inverse relationship between

19 MSNA burst frequency during moderate submaximal leg cycling exercise and peak VO2 in

20 subjects with and without HFrEF, independent of resting MSNA (Notarius et al., 2014) (Figure

21 2). This link between MSNA during dynamic exercise and peak exercise capacity gives further

22 support to the concept of a neurogenic limit to exercise in HFrEF. This relationship was not

23 observed by others during static handgrip exercise (Kuniyoshi et al., 2014). Further, we

24 hypothesized that, in contrast to the drop in MSNA observed previously in young healthy control 
1 subjects during dynamic one-legged cycling (Ray et al., 1993), MSNA would increase in patients

2 with HFrEF. Indeed, we found divergent MSNA responses to both 2 minutes of mild (unloaded)

3 and moderate (50\% of VO2peak) one-legged cycling, in HFrEF compared with age-matched

4 control subjects. Despite having similar heart rate responses MSNA burst frequency increased

5 during both intensities of exercise in HFrEF patients but fell in control subjects, (Notarius et al.,

6 2015) (Figure 3). These recent results provided the first direct evidence of increased sympathetic

7 outflow to the calf muscle during dynamic leg exercise in HFrEF, and were linked to reduced

8 exercise capacity.

9 The current literature regarding MSNA responses to exercise in HFrEF cohorts is summarized in Table 2. In sum, MSNA during handgrip exercise in HFrEF is activated by a

11 lower intensity threshold compared with age-matched control subjects, whereas the exercise-

12 induced response to mild and moderate dynamic leg cycling is qualitatively different from

13 healthy controls. The functional consequence of such sympathoexcitation is likely peripheral

14 vasoconstriction which could directly impact exercise tolerance by limiting skeletal muscle

15 blood flow in HFrEF. The precise mechanism for the divergent MSNA responses to dynamic leg

16 exercise requires further investigation but is likely to involve recruitment of sympathoexcitatory

17 reflexes (muscle metabo- and mechano-, cardiopulmonary baro- and arterial chemoreceptor 18 reflexes).

Neural adaptations following a single bout of exercise might anticipate the response to

22 exercise training (Floras et al., 1989). Almost twenty years ago, our group compared MSNA

23 after moderate intensity treadmill exercise in young HFrEF patients with dilated cardiomyopathy 
1 to that of age-matched controls. Despite marked peripheral vasodilation post-exercise, we found

2 no reflex increase in MSNA in either group, suggesting acute arterial baroreceptor reflex

3 resetting. Further, stroke volume and systolic blood pressure were higher post-exercise in HFrEF

4 patients (consistent with the failing ventricle's response to afterload reduction) but not in

5 controls. These findings suggested that by lowering peripheral resistance and increasing stroke

6 volume, exercise training might be an important non-pharmacological therapy for HFrEF

7 patients (Hara and Floras, 1996).

8 The specific effect of exercise training on resting and exercise MSNA in HFrEF patients

9 has received limited attention. In a series of studies, 4 months of exercise training (25-40 minutes

10 of cycling exercise plus warm up and cool down, 3 times per week at a heart rate of $10 \%$ less

11 than anaerobic threshold) in patients with HFrEF normalized resting MSNA and reduced forearm

12 vascular resistance (Roveda et al., 2003; Fraga et al., 2007). This response was independent of

13 both age (Antunes-Correa et al., 2012) and gender (Antunes-Correa et al., 2010). However, only

14 one study by Soares-Miranda et al., also from this group, recorded MSNA during exercise

15 (Soares-Miranda et al., 2011). They compared MSNA and forearm vascular resistance responses

16 during static handgrip in age-matched controls and two HFrEF groups, one untrained and the

17 other before and after 4 months of dynamic exercise training. Elevated MSNA during static

18 handgrip in the untrained HFrEF group was normalized by exercise training. The authors

19 attributed this drop to the reduction in baseline MSNA. Such a reduction has important

20 implications for improving outcomes in this patient population. However, whether this training

21 response occurs during dynamic leg exercise in HFrEF, which is a more clinically relevant

22 intervention, is unknown. This remains a fertile area for investigation. 


\section{FUTURE DIRECTIONS}

Evidence of elevated MSNA both at rest and during dynamic leg exercise in HFrEF, in contrast to healthy control subjects, now sets the stage for future studies to elucidate the mechanisms responsible for such sympathoexcitation. Diminished sympathoinhibitory mechanisms such as the cardiopulmonary baroreflex and enhanced excitatory reflexes such as the muscle metaboreflex, mechanoreflex, and arterial chemoreceptor must be systematically evaluated with respect to their role in the augmented sympathetic response to dynamic leg exercise in HFrEF patients. Whether patients with heart failure with preserved ejection fraction (HFpEF) also exhibit a similar MSNA response during this type of exercise is also an open question. The functional significance of sympathoexcitation during dynamic leg exercise on blood flow in HFrEF, and the relationship between changes in MSNA and $\mathrm{VO}_{2}$ peak and the effects of exercise training on related mechanisms remain to be established. In healthy men and women the independent effect of aging on the MSNA response during dynamic leg cycling has yet to be addressed definitively.

\section{CONCLUSIONS}

In summary, sympathetic activity at rest, evaluated directly by microneurography, varies widely between young and older healthy subjects and HFrEF patients. MSNA responses to exercise are a function of exercise type, intensity and posture. In the HFrEF population, baseline fitness level, etiology of HFrEF, and presence of sleep apnea also influence sympathetic nerve firing rates. The inverse relationship between exercise capacity and changes in MSNA during cycling in middle-aged subjects with and without HFrEF supports a potential role for exercise 
1 training in reducing sympathoexcitation in those at most risk. The contributions of altered

2 sympathoinhibitory (cardiopulmonary baroreflex) or exaggerated sympathoexcitatory (muscle

3 metaboreflex and mechanoreflex; arterial chemoreflex; cardiopulmonary baroreflex) reflexes

4 during exercise in human HFrEF remain to be elucidated. This represents an important avenue

5 for future research in order to identify more effective targeted exercise interventions and

6 therapies. 
1

\section{REFERENCES}

Abboud, F. and Kumar, R. 2014. Obstructive sleep apnea and insight into mechanisms of sympathetic overactivity. J.Clin. Invest. 124: 1454-1457.

Alvarez,G.E., Halliwill,J.R., Ballard,T.P., Beske,S.D., Davy,K.P. 2005. Sympathetic neural regulation in endurance-trained humans: fitness vs fatness. J. Appl. Physiol. 98:498-502.

Alves, M.J., Rondon, M.U., Santos, A.C., Dias, R.G., Barretto, A.C., Krieger, E.M., Middlekauff, H.R., and Negrao, C.E. 2007. Sympathetic nerve activity restrains reflex vasodilation in heart failure. Clin. Auton. Res. 17: 364-369.

Alves, M.J.N.N., dos Santos, M.R., Nobre, T.S., Martinez, D.G., Barretto, A.C.P., Brum, P.C., Rondon, M.U.P.B., Middlekauff, H.R., and Negrao, C.E. 2012. Mechanisms of blunted vasodilation during peripheral chemoreceptor stimulation in heart failure patients. Hypertension 60: $669-676$.

Andersen, P., Adams, R.P., Sjoqaard, G., Thorboe, A., and Saltin, B. 1985. Dynamic knee extension as model for study of isolated exercising muscle in humans. J. Appl. Physiol. 59: 1653.

Ando, S., Dajani, H.R., and Floras, J.S. 1997a. Frequency domain characteristics of muscle sympathetic nerve activity in heart failure and healthy humans. Am. J. Physiol. 273: R205-R212. 
1 Ando, S., Dajani, H.R., Senn, B.L., Newton, G.E., and Floras, J.S. 1997b. Sympathetic alternans.

2 Evidence for arterial baroreflex control of muscle sympathetic nerve activity in congestive heart

3 failure. Circ. 95: 316-319.

4 Antunes-Correa, L.M., Kanamura, B.Y., Melo, R.C., Nobre, T.S., Ueno, L.M., Franco, F.G.,

5 Roveda, F., Braga, A.M., Rondon, M.U., Brum, P.C., Barretto, A.C., Middlekauff, H.R., and

6 Negrao, C.E. 2012. Exercise training improves neurovascular control and functional capacity in

7 heart failure patients regardless of age. Eur. J. Prev. Cardiol. 19: 822-829.

8 Antunes-Correa, L.M., Melo, R.C., Nobre, T.S., Ueno, L.M., Franco, F.G., Braga, A.M.W.,

9 Rondon, M.U.P.B., Brum, P.C., Barretto, A.C.P., Middlekauf, H.R., and Negrao, C.E. 2010.

10 Impact of gender on benefits of exercise training on sympathetic nerve activity and muscle blood

11 flow in heart failure. Eur. J. Heart Fail. 12: 58-65.

12 Azevedo, E.R., Newton, G.E., Floras, J.S., and Parker, J.D. 2000. Reducing cardiac filling

13 pressure lowers norepinephrine spillover in patients with chronic heart failure. Circ. 101: 2053142059.

15 Azevedo, E.R., Newton, G.E., and Parker, J.D. 1999. Cardiac and systemic sympathetic activity 16 in response to clonidine in human heart failure. J. Am. Coll. Cardiol. 33: 186-191.

17 Barretto, A.C.P., Santos, A.C., Munhoz, R., Rondon, M.U.P.B., Franco, F.G., Trombetta, I.C.,

18 Roveda, F., De Matos, L.D.N.J., Braga, A.M.W., Middlekauf, H.R., and Negrao, C.E. 2009. 
1 Increased muscle sympathetic nerve activity predicts morality in heart failure patients. Int. J.

2 Cardiol. 135: 302-307.

3 Batman, B.A., Hardy, J.C., Leuenberger, U.A., Smith, M.B., Yang, Q.X., and Sinoway, L.I.

4 1994. Sympathetic nerve activity during prolonged rhythmic forearm exercise. J. Appl. Physiol.

5 76: 1077-1081.

6 Carter, J.R. and Ray, C.A. 2015. Sympathetic neural adaptations to exercise training in humans.

7 Autonomic Neuroscience:Basic and Clinical, 188: 36-43.

8 Carter, J.R., Ray, C.A., Downs, E.M., and Cooke, W.H. 2003. Strength training reduces arterial

9 blood pressure but not sympathetic activity in young normotensive subjects. J.Appl.Physiol. 94:

$10 \quad 2212-2216$.

11 Charkoudian, N., Joyner, M.J., Sokolnicki, L.A., Johnson, C.P., Eisenach, J.H., Dietz, N.M.,

12 Curry, T.B., and Wallin, B.G. 2006. Vascular adrenergic responsiveness is inversely related to

13 tonic activity of sympathetic vasoconstrictor nerves in humans. J.Physiol. 572.3: 821-827.

14 Cohn, J.N., Johnson, G.R., Shabetai, R., Loeb, H., Tristani, F., Rector, T., Smith, R., Fletcher, 15 R., and. for the V-HeFT VA Cooperative Studies Group 1993. Ejection fraction, peak exercise 16 oxygen consumption, cardiothoracic ratio, ventricular arrhythmias, and plasma norepinephrine as 17 determinants of prognosis in heart failure. Circ. 87: VI-5-VI-16. 
1 Cohn, J.N., Levine, T.B., Olivari, M.T., Garberg, V., Lura, D., Francis, G.S., and Simon, A.

2 1984. Plasma norepinephrine as a guide to prognosis in patients with chronic congestive heart

3 failure. N. Engl. J. Med. 311: 819-823.

4 Crisafulli, A., Salis, E., Tocco, F., Melis, F., Milia, R., Pittau, G., Caria, M.A., Solinas, R.,

5 Meloni, L., Pagliara, P., and Concu, A. (2007). Impaired central hemodynamic response and

6 exaggerated vasoconstriction during muscle metaboreflex activation in heart failure patients.

7 Am. J. Physiol. 292: H2988-H2996.

8 Despas, F., Lambert, E., Vaccaro, A., Labrunee, M., Franchitto, N., Lebrun, M., Galinier, M.,

9 Senard, J.M., Lambert, G., Esler, M., and Pathak, A. (2012). Peripheral chemoreflex activation

10 contributes to sympathetic baroreflex impairment in chronic heart failure. J. Hypertens. 30: 753-

11760.

12 Dibner Dunlap, M.E., Smith, M.L., Kinugawa, T., and Thames, M.D. 1996. Enalaprilat

13 augments arterial and cardiopulmonary baroreflex control of sympathetic nerve activity in

14 patients with heart failure. J. Am. Coll. Cardiol. 27: 358-364.

15 Dinenno, F.A., Jones, P.P., Seals, D.R., and Tanaka, H. 1999. Limb blood flow and vascular

16 conductance are reduced with age in healthy humans: Relation to elevations in sympathetic nerve

17 activity and declines in oxygen demand. Circ. 100: 164-170. 
1 Esler, M., Jennings, G.L., Korner, P., Willett, I., Dudley, F., Hasking, G.J., Anderson, W., and

2 Lambert, G. 1988. Assessment of human sympathetic nervous system activity from

3 measurements of norepinephrine turnover. Hypertension, 11: 3-20.

4 Esposito, F., Mathieu-Costello, O., Shabetai, R., Wagner, P.D., and Richardson, R.S. 2010.

5 Limited maximal exercise capacity in patients with chronic heart failure: Partitioning the

6 contributors. J. Am. Coll. Cardiol. 55: 1945-1955.

7 Ferguson, D.W., Berg, W.J., and Sanders, J.S. 1990. Clinical and hemodynamic correlates of

8 sympathetic nerve activity in normal humans and patients with heart failure: evidence from

9 direct microneurographic recordings. J. Am. Coll. Cardiol. 16: 1125-1134.

10 Floras, J.S. 2001. Arterial baroreceptor and cardiopulmonary reflex control of sympathetic

11 outflow in human heart failure. Ann. NY Acad. Sci. 940: 500-513.

12 Floras, J.S. 2009. Sympathetic nervous system activation in human heart failure: clinical

13 implications of an updated model. J. Am. Coll. Cardiol. 54: 375-385.

14 Floras, J.S. and Hara, K. 1993. Sympathoneural and hemodynamic characteristics of young 15 subjects with mild essential hypertension. J.Hypertens. 11: 647-655.

16 Floras, J.S., Jones, J.V., Hassan, M.O., Osikowska, B.A., Sever, P.S., and Sleight, P. 1986.

17 Failure of plasma norepinephrine to consistently reflect sympathetic activity in humans.

18 Hypertension, 8: 641-649. 
1 Floras, J.S., and Ponikowski, P. 2015. The sympathetic/parasympathetic balance in heart failure

2 with reduced ejection fraction. Eur. Heart J. [Epub ahead of print].

3 Floras, J.S., Sinkey, C.A., Alyward, P.E., Seals, D.R., Thoren, P.N., and Mark, A.L. 1989.

4 Postexercise hypotension and sympathoinhibition in borderline hypertensive men. Hypertension, 5 14: $28-35$.

6 Forster, C., and Armstrong, P.W. 1990. Pacing-induced heart failure in the dog: evaluation of

7 peripheral vascular alpha-adrenoceptor subtypes. J. Cardiovasc. Pharmacol. 16: 708-718.

8 Forester, C., Carter, S., Armstrong, P. 1989. Vascular smooth muscle responsiveness to

9 noradrenaline and phenylephrine following experimental heart failure in dogs. Cardiovasc. Res.

$10 \quad 23: 489-497$.

11 Fraga, R., Franco, F.G., Roved,a F., de Matos, L.N., Braga, A.M.W., Rondon, M.U.P.B., Rotta,

12 D.R., Brum, P.C., Barretto, A.C.P., Middlekauf, H.R., and Negrao, C.E. 2007. Exercise training 13 reduces sympathetic nerve activity in heart failure patients treated with carvedilol. Eur. J. Heart 14 Fail. 9: 630-636.

15 Franciosa, J.A., Park, M., and Levine, T.B. 1981. Lack of correlation between exercise capacity 16 and indexes of resting left ventricular performance in heart failure. Am. J. Cardiol. 47: 33-39. 
1 Grassi, G., Bolla, G., Quarti-Trevano, F., Arenare, F., Brambilla, G., and Mancia, G. 2008.

2 Sympathetic activation in congestive heart failure: reproducability of neuroadrenergic markers.

3 Eur. J. Heart Fail. 10: 1186-1191.

4 Grassi, G. and Esler, M. 1999. How to assess sympathetic activity in humans. J. Hypertens. 17:

$5 \quad 719-734$.

6 Grassi, G., Seravalle, G., Brambilla, G., Buzzi, S., Volpe, M., Cesana, F., Dell'Oro, R., and

7 Mancia, G. 2014. Regional differences in sympathetic activation in lean and obese

8 normotensives individuals with obstructive sleep apnoea. J. Hypertens. 32: 383-388.

9 Hammond, R.L., Augustyniak, R.A., Rossi, N.F., Churchill, P.C., Lapanowsky, K., O'Leary, 10 D.S. 2000. Heart failure alters the strength and mechanisms of the muscle metaboreflex. Am. J.

11 Physiol. 278: H818-H828.

12 Hansen, J., Thomas, G.D., Jacobsen, T.N., and Victor, R.G. 1994. Muscle metaboreflex triggers 13 parallel sympathetic activation in exercising and resting human skeletal muscle. Am. J. Physiol. 14 266: H2508-H2514.

15 Hara, K. and Floras, J.S. 1996. After-effects of exercise on hemodynamics and sympathetic 16 nerve activity in young subjects with dilated cardiomyopathy. Heart, 75: 602-608. 
1 Hart, E.C., Charkoudian, N., Wallin, B.G., Curry, T.B., Eisenach, J.H., and Joyner, M.J. 2009.

2 Sex differences in sympathetic neural-hemodynamic balance: implications for human blood

3 pressure regulation. Hypertension, 53:571-576.

4 Hasking, G.J., Esler, M.D., Jennings, G.L., Burton, D., Johns, J.A., and Korner, P.I. 1986.

5 Norepinephrine spillover to plasma in patients with congestive heart failure: evidence of

6 increased overall and cardiorenal sympathetic nervous activity. Circ. 73: 615-621.

7 Hasking, G.J., Esler, M.D., Jennings, G.L., Dewar, E., and Lambert, G. 1988. Norepinephrine

8 spillover to plasma during steady-state supine bicycle exercise: comparison of patients with

9 congestive heart failure and normals subjects. Circ. 78: 516-521.

10 Ichinose, M., Saito, M., Fujii, N., Ogawa, T., Hayashi, K., Kondo, N., and Nishiyasu, T. 2008.

11 Modulation of the control of muscle sympathetic nerve activity during incremental leg cycling. J.

12 Physiol. 586: 2753-2766.

13 Jensen, E.W., Espersen, K., Kanstrup, I.L., and Christensen, N.J. 1994. Exercise-induced changs

14 in plasma catecholamines and neuropeptide Y: relation to age and sampling times. J. Appl.

15 Physiol. 76: 1269-1273.

16 Katayama, K., Ishida, K., Iwamoto, E., Iemitsu, M., Koike, T., and Saito, M. 2011. Hypoxia

17 auments muscle sympathetic neural response to leg cycling. Am. J. Physiol. 301: R456-R464. 
1 Kaye, D.M., Lefkovits, J., Jennings, G.L., Bergin,. P, Broughton,. A, and Esler, M.D. 1995.

2 Adverse consequences of high sympathetic nerve activity in the failing human heart. J. Am. Coll.

3 Cardiol. 26: 1257-1263.

4 Kingwell, B.A., Thompson, J.M., McPherson, G.A., Kaye, D.M., Jennings, G.L, and Esler, M.D.

5 1995. Comparison of heart rate spectral analysis with cardiac noradrenaline spillover and muscle

6 sympathetic nerve activity in human subjects. In Computer Analysis of Cardiovascular Signals,

7 eds. Di Rienzo M, Mancia G, Parati G, Pedotti A, and Zanchetti A, pp. 167-176. IOS Press,

8 Amsterdam.

9 Kuniyoshi, R.R., Matinelli, M., Negrao, C.E., Siqueira, S.F., Rondon, M.U., Trombetta, I.C.,

10 Kuniyoshi, F..H, Laterza, M.C., Nishioka, S.A., Costa, R., Tamaki, W.T., Crevelari, E.S.,

11 Peizoto, G.D., Ramires, J.A., and Kalil, R. 2014. Effects of cardiac resynchronization therapy on

12 muscle sympathetic nerve activity. Pacing Clin Electrophysiol 37: 11-18.

13 Lang, C.C., Rayos, G.H., Chomsky, D.B., Wood, A.J.J., and Wilson, J.R. 1997. Effect of

14 sympathoinhibition on exercise performance in patients with heart failure. Circ. 96: 238-245.

15 Leimbach, W.N., Wallin, B.G., Victor, R..G, Aylward, P.E., Sundlof, G., and Mark, A.L. 1986.

16 Direct evidence from intraneural recordings for increased central sympathetic outflow in patients

17 with heart failure. Circ. 73: 913-919.

18 Mark, A.L., Victor, R.G., Nerhed, C., and Wallin, B.G. 1985. Microneurographic studies of the

19 mechanisms of sympathetic nerve responses to static exercise in humans. Circ. Res. 57: 461-469. 
1 Middlekauff, H.R., Chiu, J., Hamilton, M.A., Fonarow, G.C., MacLellan, W.R., Hage, A.,

2 Moriguchi, J., and Patel, J. 2004. Muscle mechanoreceptor sensitivity in heart failure. Am. J.

3 Physiol. 287: H1937-H1943.

4 Middlekauff, H..R and Sinoway, L.I. 2007. Point: Increased mechanoreceptor stimulation

5 explains the exaggurated exercise pressor reflex seen in heart failure. J. Appl. Physiol. 102: 492-

6494.

7 Millar, P.J., Murai, H., and Floras, J.S. 2015. Paradoxical muscle sympathetic reflex activation in

8 human heart failure. Circ. 131: 459-468.

9 Millar, P.J., Murai, H., Morris, B.L., and Floras, J.S. 2013. Microneurographic evidence in 10 middle-aged healthy humans for a sympathoexcitatory reflex activated by atrial pressure.

11 Am.J.Physiol. 305: H931-H938.

12 Mitchell, J.H. 1990. J.B. Wolffe memorial lecture. Neural control of the circulation during 13 exercise. Med. Sci. Sports Exerc. 22: 141-154.

14 Moreau, K.I., Donato, A.J., Tanaka, H., Jones, P.P., Gates, P.E., and Seals, D.R. 2003. Basal leg 15 blood flow in healthy women is related to age and hormone replacement therapy status. J.

16 Physiol. 547: 309-316.

17 Murai, H., Takamura, M., Maruyama, M., Nakano, M., Ikeda, T., Kobayash,i D., Otowa, K.,

18 Ootsuji, H., Okajima, M., Furusho, H., Takata, S., and Kaneko, S. 2009. Altered firing pattern of 
1 single-unit muscle sympathetic nerve activity during handgrip exercise in chronic heart failure. J.

2 Physiol. 587: 2613-2622.

3 Ng, A.V., Callister, R., Johnson, D.G., and Seals, D.R. 1993. Age and gender influence muscle

4 sympathetic nerve activity at rest in healthy humans. Hypertension, 21: 498-503.

5 Notarius, C.F., Ando, S., Rongen, G.A., and Floras, J.S. 1999a. Resting muscle sympathetic

6 nerve activity and peak oxygen uptake in heart failure and normal subjects. Eur. Heart J. 20: 8807887.

8 Notarius, .CF., Atchison, D.J., and Floras, J.S. 2001. Impact of heart failure and exercise 9 capacity on sympathetic response to handgrip exercise. Am. J. Physiol. 280: H969-H976.

10 Notarius, C.F., Azevedo, E.R., Parker, J.D., and Floras, J.S. 2002. Peak oxygen uptake is not 11 determined by cardiac noradrenaline spillover in heart failure. Eur. Heart J. 23; 800-805.

12 Notarius, C.F., Butler, G.C., Ando, S., Pollard, M.J., Senn, B., and Flora, J.S. 1999 b.

13 Dissociation between microneurographic and heart rate variability estimates of sympathetic tone 14 in normal subjects and patients with heart failure. Clin. Sci. 96: 557-565.

15 Notarius, C.F. and Floras, J.S. 2007. Point:counterpoint: Increased

16 mechanoreceptor/metaboreceptor stimulation explains the exaggerated exercise pressor reflex

17 seen in heart failure. J. Appl. Physiol. 102: 824. 
1 Notarius, C.F., Millar, P.J., Murai, H., Morris, B.L., and Floras, J.S. 2014. Inverse relationship

2 between muscle sympathetic nerve activity during exercise and peak oxygen uptake in subjects

3 with and without heart failure. J. Am. Coll. Cardiol. 63: 605-606.

4 Notarius, C.F., Millar, P.J., Murai, H., Morris, B.L., Marzolini, S., Oh, P., and Floras, J.S. 2015.

5 Divergent muscle sympathetic responses to dynamic leg exercise in heart failure and age-

6 matched healthy subjects. J. Physiol. 593: 715-722.

7 Notarius, C.F., Morris, B.L., and Floras, J.S. 2009. Dissociation between reflex sympathetic and

8 forearm vascular responses to lower body negative pressure in heart failure patients with

9 coronary artery disease. Am. J. Physio.1 297: H1760-H1766.

10 Notarius, C.F., Mura,i H., Morris, B.L., and Floras, J.S. 2012. Effect of fitness on reflex

11 sympathetic neurovascular transduction in middle-aged men. Med. Sci. Sports Exerc. 44: 232-

12237.

13 Notarius, C.F., Spaak, J., Morris, B.L., and Floras, J.S. 2007. Comparison of muscle sympathetic

14 activity in ischemic and nonischemic heart failure. J. Cardiac Fail. 13: 470-475.

15 Petersson, M., Friberg, P., Eisenhofer, G., Lambert, G., and Rundqvist, B. 2005. Long-term

16 outcome in relation to renal sympathetic activity in patients with chronic heart failure. Eur. Heart

17 J. 26: 906-913. 
1 Piepoli, M. and Coats, A.J.S. 2007. Counterpoint: Increased metaboreceptor stimulation explains

2 the exaggurated exercise pressor reflex seen in heart failure. J. Appl. Physiol. 102: 494-496.

3 Pina, I.L., Apstein, C.S., Balady, G.J., Belardinelli,R., Chaitman,,B.R., Duscha,B.D., Fletcher,

4 B.J. Fleg, J.L. Myers, J.N. Sullivan, M.J. 2003. Exercise and Heart Failure: A Statement From

5 the American Heart Association Committee on Exercise, Rehabilitation, and Prevention. Circ.

$6 \quad$ 107:1210-25.

7

8 Ray, C.A. 1999. Sympathetic adaptations to one-legged training. J. Appl. Physiol. 86: 158391587.

10 Ray, C.A. and Carrasco, D. 2000. Isometric handgrip training reduces arterial pressure at rest

11 without changes in sympathetic activity. Am. J. Physiol. 279: H245-H249.

12 Ray, C.A., Rea, R.F., Clary, M.P., and Mark, A.L. 1993. Muscle sympathetic nerve responses to 13 dynamic one-legged exercise: effect of body posture. Am. J. Physiol. 264: H1-H7.

14 Rea, R.F. and Wallin, B.G. 1989. Sympathetic nerve activity in arm and leg muscles during 15 lower body negative pressure in humans. J, Appl, Physiol, 66: 2778-2781.

16 Roveda, F., Middlekauff, H.R., Urbana, M., Rondon, P.B., Reis, S.F., Souza, M., Nastari, L.,

17 Barretto, A.C.P., Krieger, E.M., and Negrao, C.E. 2003. The effects of exercise training on 18 sympathetic neural activation in advanced heart failure. J. Am. Coll. Cardiol. 42: 854-860. 
1 Rundqvist, B., Elam, M., Bergman-Sverrisdottir, Y., Eisenhofer, G., and Friberg, P. 1997.

2 Increased cardiac adrenergic drive precedes generalized sympathetic activation in human heart

3 failure. Circ. 95: 169-175.

4 Saito, M., Iwase, S., and Hachiya, T. 2009. Resistance exercise training enhances sympathetic

5 nerve activity during fatigue-inducing isometric handgrip trials. Eur. J. Appl. Physiol. 105 2256234.

7 Saito, M. and Mano, T. 1991. Exercise mode affects muscle sympathetic nerve responsiveness.

$8 \quad$ Jpn. J. Physiol. 41: 143-151.

9 Saito, M., Tsukanaka, A., Yanagihara, D., and Mano, T. 1993. Muscle sympathetic nerve 10 responses to graded leg cycling. J. Appl. Physiol. 75: 663-667.

11 Santos, A.C., Alves, M.J.N.N., Rondon, M.U.P.B., Barretto, A.C.P., Middlekauff, H.R., and

12 Negrao, C.E. 2005. Sympathetic activation restrains endothelium-mediated muscle vasodilation

13 in heart failure patients. Am. J. Physiol. 289: H593-599.

14 Schultz, H.D., Li, Y.L., and Ding, Y. 2007. Arterial chemoreceptors and sympathetic nerve 15 activity: implications for hypertension and heart failure. Hypertension, 50: 6-13.

16 Seals, D.R. 1991. Sympathetic neural adjustments to stress in physically trained and untrained 17 humans. Hypertension, 17: 36-43. 
1 Seals, D.R. and Esler, M.D. 2000. Human ageing and the sympathoadrenal system. J. Physiol.

2 528: $407-417$.

3 Sheldahl, L.M., Ebert, T.J., Cox, B., and Tristani, F.E. 1994. Effect of aerobic training on

4 baroreflex regulation of cardiac and sympathetic function. J. Appl. Physiol. 76: 158-165.

5 Silber, D.H., Sutliff, G., Yang, Q.X., Smith, M.B., Sinoway, L.I., and Leuenberger, U. 1998.

6 Altered mechanisms of sympathetic activation during rhythmic forearm exercise in heart failure.

$7 \quad$ J. Appl. Physiol. 84: 1551-1559.

8 Sinoway,L.I., Rea,R.F., Mosher,T.J., Smith,M.B., Mark,A.L. 1992. Hydrogen ion concentration

9 is not the sole determinant of muscle metaboreceptor responses in humans. J. Clin. Invest.

$10 \quad 89: 1875-1884$.

11 Sinoway, L.I., Shenberger, J., Leaman, G., Zelis, R., Gray, K., Baily, R. and Leuenberger, U.

12 1996. Forearm training attenuates sympathetic responses to prolonged rhythmic forearm

13 exercise. J. Appl. Physiol. 81: 1778-1784.

14 Soares-Miranda, L., Franco, F.G., Roveda, F., Martinez, D.G., Rondon, M.U.P.B., Mota, J.,

15 Brum, P.C., Antunes-Correa, L.M., Nobre, T.S., Barretto, A.C.P., Middlekauff, H.R., and

16 Negrao, C.E. 2011. Effects of exercise training on neurovascular responses during handgrip

17 exercise in heart failure patients. Int. J. Cardiol. 146: 122-125. 
1 Somers, V.K., Leo, K.C., Shields, R., Clary, M., and Mark, A.L. 1992. Forearm endurance

2 training attenuates sympathetic nerve response to isometric handgrip in normal humans. J. Appl.

3 Physiol. 72: 1039-1043.

4 Spaak, J., Egri, Z.J., Kubo, T., Yu, E., Ando, S., Kaneko, Y., Usui, K., Bradley, T.D., and Floras,

5 J.S. 2005. Muscle sympathetic nerve activity during wakefulness in heart failure patients with

6 and without sleep apnea. Hypertension, 46: 1327-1332.

7 Stelken, A.M., Younis, L.T., Jennison, S.H., Miller, D.D., Miller, L.W., Shaw, L.J., Kargl, D.,

8 and Chaitman, B.R. 1996. Prognostic value of cardiopulmonary exercise testing using percent

$9 \quad$ achieved of predicted peak oxygen uptake for patients with ischemic and dilated

10 cardiomyopathy. J. Am. Coll. Cardiol. 27: 345-352.

11 Sterns, D.A., Ettinger, S.E., Gray, K.S., Whisler, S.K., Mosher, T.J., Smith, M.B., and Sinoway,

12 L.I. 1991. Skeletal muscle metaboreceptor exercise responses are attenuated in heart failure.

13 Circ. 84: 2034-2039.

14 Stickland, M.K., Fuhr, D.P., Haykowsky, M.J., Jones, K.E., Paterson, D.I., Ezekowitz, J.A., and

15 McMurtry, M.S. 2011. Carotid chemoreceptor modulation of blood flow during exercise in

16 healthy humans. J. Physiol. 589.24: 6219-6230.

17 Stickland, M.K. and Miller, J.D. 2008. Carotid chemoreceptor modulation of sympathetic

18 vasoconstrictor outflow during exercise in healthy humans. J. Physiol. 586: 1743-1754. 
1 Svedenhag, J., Wallin, B.G., Sundlof, G., and Henriksson, J. 1984. Skeletal muscle sympathetic

2 activity at rest in trained and untrained subjects. Acta. Physiol. Scand. 120: 499-504.

3 Task Force of European Society of Cardiology and North American Society of Pacing and

4 Electrophysiology. 1996. Heart rate variability: standards of meaurements, physiological

5 interpretation, and clinical use. Circ. 93: 1043-1065.

6 Usui, K., Bradley, T.D., Spaak, J., Ryan, C.M., Kubo, T., Kaneko, Y., and Floras, J.S. 2005.

7 Inhibition of awake sympathetic nerve activity of heart failure patients with obstructive sleep

8 apnea by nocturnal continuous positive airway pressure. J. Am. Coll. Cardiol. 45: 2008-2011.

9 Valbo, A.B., Hagbarth, K.E., Torebjork, H.E., and Wallin, B.G. 1979. Somatosensory,

10 proprioceptive, and sympathetic activity in human peripheral nerves. Physiol. Rev. 59: 919-957.

11 Valbo, A.B., Hagbarth, K.E., and Wallin, B.G. 2004. Microneurography: how the technique

12 developed and its role in the investigation of the sympathetic nervous system. J. Appl. Physiol.

13 96: $1262-1269$.

14 Victor, R.G., Seals, D.R., and Mark, A.L. 1987. Differential control of heart rate and sympathetic 15 nerve activity during dynamic exercise. J. Clin. Invest. 79: 508-516. 
Table 1. Effects of exercise on muscle sympathetic nerve activity (MSNA) in healthy subjects.

\begin{tabular}{|c|c|c|c|c|}
\hline Reference & Population & $\begin{array}{c}\text { Exercise } \\
\text { Intervention } \\
\end{array}$ & $\begin{array}{c}\text { Nerve } \\
\text { Studied }\end{array}$ & Effects on MSNA during exercise \\
\hline Mark et al. 1985 & $\begin{array}{l}14 \text { men; } 6 \text { women } \\
20-56 \text { years of age }\end{array}$ & Static HG (30\% MVC) & Fibular & $\begin{array}{l}\Uparrow \text { burst frequency and total MSNA during second } \\
\text { minute of exercise }\end{array}$ \\
\hline Victor et al. 1987 & $\begin{array}{l}22 \text { men; } 3 \text { women } \\
18-30 \text { years of age }\end{array}$ & Dynamic HG (30\% MVC) & Fibular & $\begin{array}{l}\Leftrightarrow ; \\
\Uparrow \text { only when ischemia added }\end{array}$ \\
\hline Saito and Mano 1991 & $\begin{array}{l}8 \text { men } \\
21 \pm 2 \text { years of age }\end{array}$ & $\begin{array}{l}\text { 1-leg cycling }(\leq 30 \% \text { VO2peak }) \\
\text { 1-leg static knee extension } \\
(20 \% \text { MVC) }\end{array}$ & Tibial & $\begin{array}{l}\Downarrow \\
\Uparrow\end{array}$ \\
\hline Saito et al. 1993 & $\begin{array}{l}8 \text { men } \\
24.5 \pm 3.3 \text { years of } \\
\text { age }\end{array}$ & $\begin{array}{l}\text { 2-leg cycling } \\
(20,40,60,75 \% \text { of } \mathrm{VO} 2 \text { peak })\end{array}$ & Median & $\begin{array}{l}\Downarrow<40 \% \text { VO2peak; } \\
\Uparrow>40 \% \text { VO2peak }\end{array}$ \\
\hline Ray et al. 1993 & $\begin{array}{l}16 \text { men } \\
19-22 \text { years of age }\end{array}$ & $\begin{array}{l}\text { 1-leg dynamic knee extension } \\
(20,30,40 \text { Watts) }\end{array}$ & Fibular & $\Downarrow$ is greatest at mild levels \\
\hline Batman et al. 1994 & $\begin{array}{l}30 \text { men } \\
27 \pm 1(19-40 \text { years })\end{array}$ & $\begin{array}{l}\text { Dynamic HG (25\%MVC) } \\
\text { Static and dynamic HG }(40 \% \\
\text { MVC) }\end{array}$ & Fibular & $\begin{array}{l}\Uparrow \% \text { total activity after } 6 \text { min during prolonged } \\
\text { dynamic } \mathrm{HG}(25 \%) \text { for } 30 \mathrm{~min} \\
\Uparrow \% \text { total activity during } 1 \text { and } 2 \text { min dynamic } \\
\text { HG and only second minute of static } \mathrm{HG}\end{array}$ \\
\hline Hansen et al. 1994 & $\begin{array}{l}7 \text { men } \\
21-43 \text { years of age }\end{array}$ & $\begin{array}{l}\text { 1-leg static toe extension }(20 \% \\
\text { MVC) }\end{array}$ & Fibular & $\begin{array}{l}\Uparrow \text { burst frequency and total MSNA during second } \\
\text { minute of exercise in both R and L nerves }\end{array}$ \\
\hline $\begin{array}{l}\text { Stickland and Miller } \\
2008\end{array}$ & $\begin{array}{l}7 \text { men } \\
33 \pm 1(28-35 \text { years })\end{array}$ & $\begin{array}{l}\text { Dynamic HG } \\
(50 \% \mathrm{MVC})\end{array}$ & Fibular & $\begin{array}{l}\text { 介 during normoxia; } \\
\text { inhibited by hyperoxia }\end{array}$ \\
\hline Ichinose et al. 2008 & $\begin{array}{l}13 \text { men; } 2 \text { women } \\
28 \pm 1 \text { years of age }\end{array}$ & $\begin{array}{l}\text { 2-leg graded cycling } \\
\text { (mild to exhaustion } 10-190 \text { Watts) }\end{array}$ & Median & $\begin{array}{l}\text { Decrease during mild; } \\
\Uparrow>\text { moderate exercise }\end{array}$ \\
\hline Katayama et al. 2011 & $\begin{array}{l}6 \text { men } \\
22.5 \pm 1 \text { years of age }\end{array}$ & $\begin{array}{l}\text { 2-leg cycling } \\
\text { (40 and } 60 \% \text { VO2peak) }\end{array}$ & Median & $\begin{array}{l}\Leftrightarrow \text { at } 40 \% \text { VO2peak; } \\
\Uparrow \text { at } 60 \% \text { VO2peak; } \\
\Uparrow \text { both with hypoxia }\end{array}$ \\
\hline
\end{tabular}


Table 1. Summary of MSNA studies during exercise. Mean \pm Standard error. MSNA, muscle sympathetic nerve activity; MVC, maximum voluntary contraction; VO2peak, peak oxygen uptake; HG, handgrip; R, right; L, left. 
Table 2. Effects of exercise on muscle sympathetic nerve activity (MSNA) in patients with heart failure with reduced ejection fraction (HFrEF)

\begin{tabular}{|c|c|c|c|c|}
\hline Reference & Population & $\begin{array}{c}\text { Exercise } \\
\text { Intervention }\end{array}$ & $\begin{array}{l}\text { Nerve } \\
\text { Studied }\end{array}$ & Effects on MSNA during exercise \\
\hline Sterns et al. 1991 & $\begin{array}{l}9 \text { HFrEF; } 53 \pm 5 \\
8 \text { control; } 55 \pm 5\end{array}$ & Static HG (30\%MVC) & Fibular & $\begin{array}{l}\Uparrow \text { in HFrEF and controls } \\
\Uparrow \text { during PHGI in controls and } \Downarrow \text { in HFrEF }\end{array}$ \\
\hline Silber et al. 1998 & $\begin{array}{l}12 \text { HFrEF men; } \\
58 \pm 2 \\
10 \text { control men; } \\
64 \pm 2\end{array}$ & $\begin{array}{l}\text { Prolonged Dynamic HG } \\
(25 \% \text { MVC })\end{array}$ & Fibular & $\begin{array}{l}\Uparrow \text { in } \mathrm{HFrEF} \text { in first } 2 \mathrm{~min} \text { of } \mathrm{HG} \\
\Leftrightarrow \text { in healthy controls; } \\
\Uparrow \text { total activity at } 20 \mathrm{~min} \mathrm{HG}\end{array}$ \\
\hline Notarius et al. 2001 & $\begin{array}{l}14 \mathrm{HFrEF}(1 \mathrm{~F}) \\
(51 \pm 4) \\
10 \text { control }(1 \mathrm{~F}) \\
(48 \pm 4)\end{array}$ & $\begin{array}{l}\text { Static HG (30\% MVC); } \\
\text { Dynamic HG }(10,30,50 \% \text { MVC) }\end{array}$ & Fibular & $\begin{array}{l}\Uparrow \text { in HFrEF during all } \mathrm{HG} \text { and PHGI } \\
(30 \% \text { static and } 50 \% \text { dynamic only) } \\
\Leftrightarrow \text { in healthy controls }\end{array}$ \\
\hline $\begin{array}{l}\text { Middlekauff et al. } \\
2004\end{array}$ & $\begin{array}{l}12 \text { HFrEF }(49 \pm 2) \\
13 \text { control }(47 \pm 3)\end{array}$ & $\begin{array}{l}\text { Dynamic HG ( } 20 \% \text { MVC }) \\
\text { Passive exercise }\end{array}$ & Fibular & $\begin{array}{l}\Uparrow \text { in HFrEF both models; } \\
\Downarrow \text { or } \Leftrightarrow \text { in healthy controls }\end{array}$ \\
\hline Murai et al. 2009 & $\begin{array}{l}16 \mathrm{HFrEF}(5 \mathrm{~F}) \\
(62 \pm 3) \\
13 \text { control }(4 \mathrm{~F}) \\
(61 \pm 3)\end{array}$ & Static HG (30\% MVC) & Fibular & $\begin{array}{l}>\Uparrow \text { in HFrEF both multi and single unit MSNA; } \\
\Uparrow \text { in single unit firing probability in HFrEF }\end{array}$ \\
\hline Notarius et al. 2014 & $\begin{array}{l}11 \mathrm{HFrEF}(2 \mathrm{~F}) \\
(61 \pm 3) \\
11 \text { control }(2 \mathrm{~F}) \\
(55 \pm 2)\end{array}$ & 1-leg cycling moderate intensity & Fibular & $\begin{array}{l}\text { Exercise MSNA inversely correlated with } \\
\text { VO2peak independent of resting MSNA }\end{array}$ \\
\hline Kuniyoshi et al. 2014 & $\begin{array}{l}\text { HFrEF } \\
\text { Control }(50 \% \mathrm{~F})\end{array}$ & $\begin{array}{l}\text { Static HG } \\
(30 \% \mathrm{MVC})\end{array}$ & Fibular & $\begin{array}{l}\text { No correlation between MSNA during static HG } \\
\text { and VO2peak in HFrEF }\end{array}$ \\
\hline Notarius et al. 2015 & $\begin{array}{l}16 \text { HFrEF }(4 \mathrm{~F}) \\
(62 \pm 3) \\
13 \text { healthy }(3 \mathrm{~F}) \\
(56 \pm 2)\end{array}$ & $\begin{array}{l}\text { 1-leg cycling No resistance; } \\
50 \% \text { of peak VO2 }\end{array}$ & Fibular & $\begin{array}{l}\Uparrow \text { in HFrEF } \\
\Downarrow \text { in healthy controls } \\
\text { Exercise MSNA inversely correlated with } \\
\text { VO2peak }\end{array}$ \\
\hline
\end{tabular}


Table 2. Abbreviations as in Table 1. HFrEF, heart failure due to reduced ejection fraction; F, female; PHGI, post-handgrip ischemia 
2 Figure 1. MSNA varies with age in the control subjects but with peak exercise capacity or

3 VO2peak in the HFrEF patients. MSNA recordings of two healthy control subjects at rest of

4 differing age: a 60 year old (top left) and a 40 year old (bottom left), both with normal peak

5 VO2; and two HFrEF patients of similar age (40's), one with a virtually normal exercise capacity

6 of 93 percent of predicted (top right) and one with a very low peak VO2 (bottom right). MSNA,

7 muscle sympathetic nerve activity; VO2peak, peak oxygen uptake. Each multifibre MSNA nerve

8 burst is marked.

9 Figure 2. Relationships between resting muscle sympathetic nerve activity (MSNA) burst

10 frequency, MSNA during second minute (2') of submaximal (50\% of $\mathrm{VO}_{2}$ peak) leg cycling

11 exercise and percent of predicted peak oxygen uptake $\left(\mathrm{VO}_{2}\right.$ peak) presented as a three-

12 dimensional plot of individual data points and regression plane; the slope, or edge of the plane,

13 relating $\mathrm{VO}_{2}$ peak to exercise-induced MSNA is significant $(\mathrm{P}=0.03)$; the slope, or edge of the

14 plane, relating $\mathrm{VO}_{2}$ peak to resting MSNA is not $(\mathrm{P}=0.93)$. For exercise-induced MSNA adjusted

15 for baseline, $\mathrm{r}=0.59 ; \mathrm{P}=0.02$. Reprinted from Notarius et al. J.Am.Coll.Cardiol. 2014, with

16 permission.

17 Figure 3. Divergent MSNA burst frequency and incidence responses to dynamic exercise in

18 HFrEF patients and control subjects.

19 Top Panel: Mean change in mean heart rate (HR) from baseline during mild and moderate

20 dynamic leg exercise. HR increased significantly in response to increasing exercise intensity during

21 the second minute of one-legged cycling in both healthy control (white bars) and heart failure 
1 (black bars) subjects (,$+ \mathrm{P}<0.003$ for $50 \%$ vs zero load cycling) with no between-group difference $2(\mathrm{P}=0.10)$.

3 Bottom Panel: Mean change in MSNA burst frequency (bursts/min) from baseline during mild and

4 moderate dynamic leg exercise. MSNA increased decreased significantly during both exercise

5 intensities in healthy control subjects (white bars) but decreased significantly during both exercise

6 intensities in heart failure patients (black bars) $(*, \mathrm{P}<0.001 \mathrm{HFrEF}$ vs control). There was no

7 significant difference in MSNA between exercise intensities within groups $(\mathrm{P}=0.78)$. Adapted from

8 Notarius et al. J. Physiol. 2015, with permission. 


\section{Healthy Control}

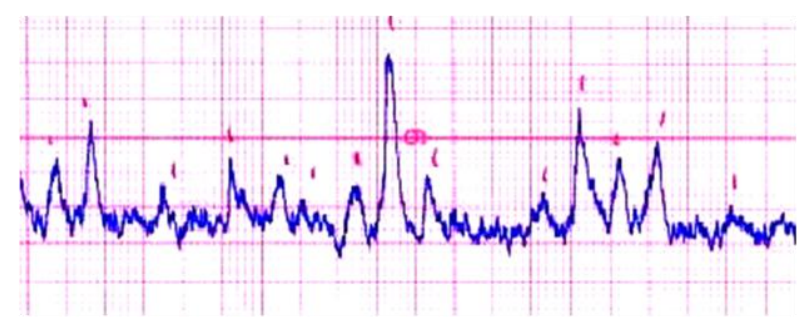

MSNA $=47$ bursts $/ \mathrm{min}$
VO2peak $=100 \%$ predicted

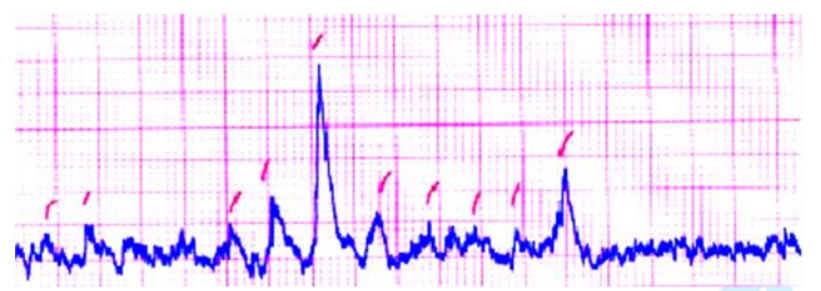

MSNA = 31 bursts $/ \mathrm{min}$ VO2peak $=90 \%$ predicted
HFrEF Patient
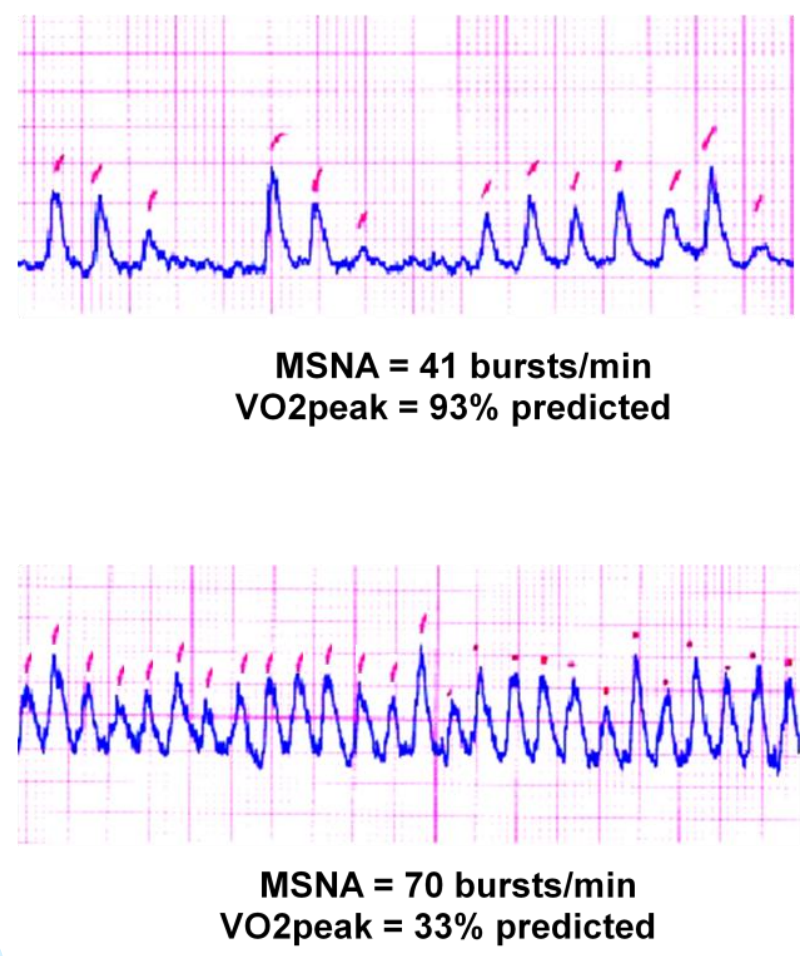


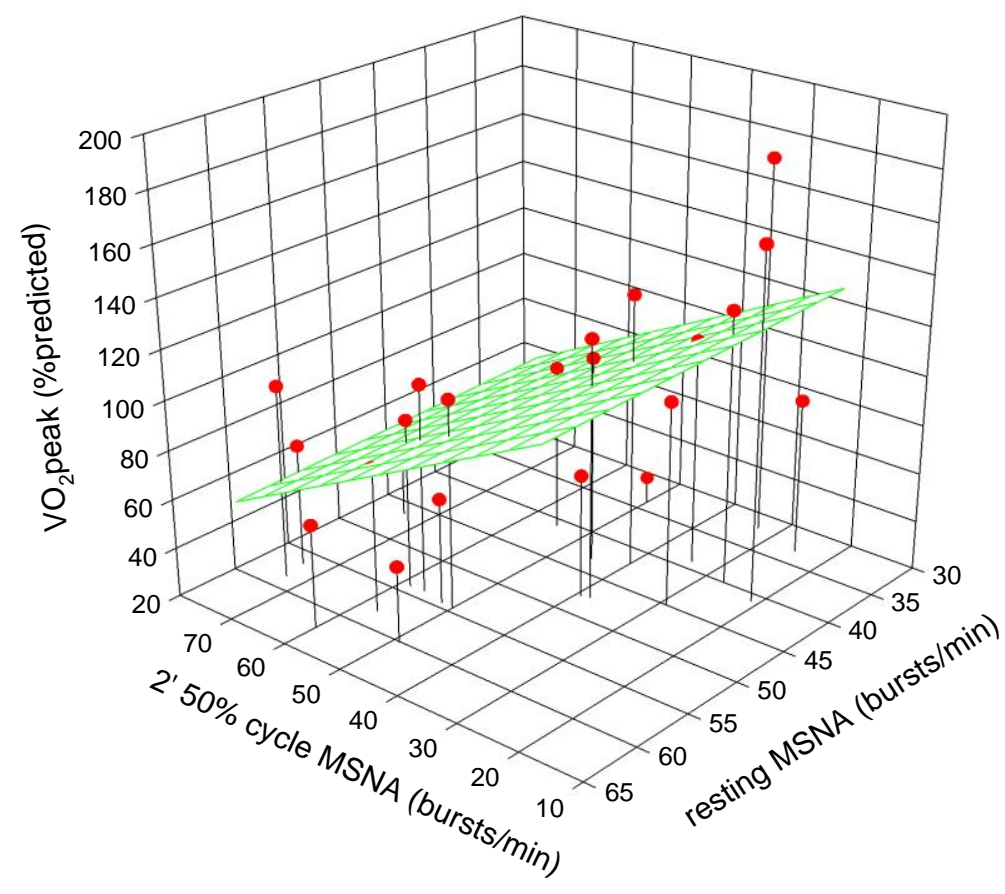



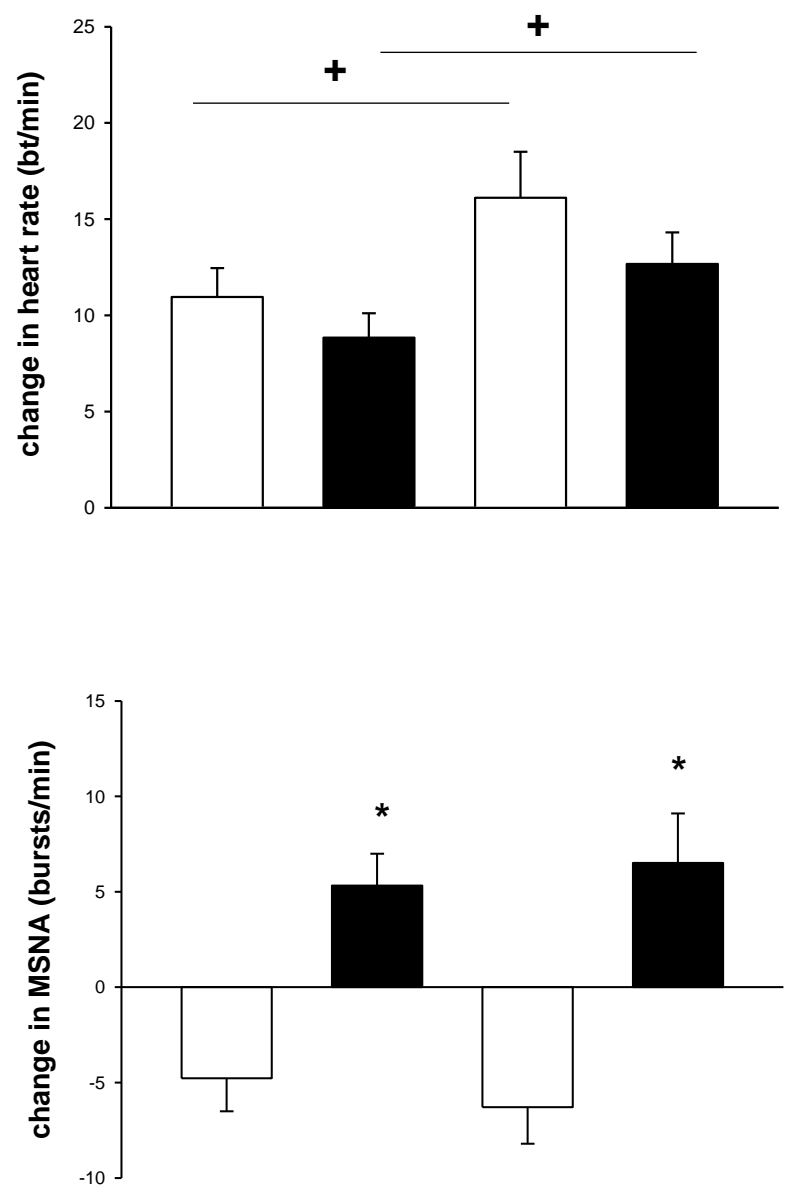

2 min 0 load cycling

2 min 50\% cycling 